\title{
Blood-brain barrier permeability of gefitinib in patients with brain metastases from non-small-cell lung cancer before and during whole brain radiation therapy
}

\author{
Yin-duo Zeng ${ }^{1, *}$, Hai Liao ${ }^{2, *}$, Tao Qin ${ }^{1, *}$, Li Zhang ${ }^{1}$, Wei-dong Wei $^{3}$, Jian-zhong \\ Liang ${ }^{4}$, Fei $\mathrm{Xu}^{1}{ }^{1}$, Xiao-xiao Dinglin ${ }^{5}$, Shu-xiang Ma ${ }^{1}$, Li-kun Chen ${ }^{1}$ \\ ${ }^{1}$ Department of Medical Oncology, Sun Yat-Sen University Cancer Center, State Key Laboratory of Oncology in South China, \\ Collaborative Innovation Center for Cancer Medicine, Guangzhou 510060, China \\ ${ }^{2}$ Lab of Phase I Clinical Study, Sun Yat-Sen University Cancer Center, State Key Laboratory of Oncology in South China, \\ Collaborative Innovation Center for Cancer Medicine, Guangzhou 510060, China \\ ${ }^{3}$ Department of Breast Oncology, Sun Yat-Sen University Cancer Center, State Key Laboratory of Oncology in South China, \\ Collaborative Innovation Center for Cancer Medicine, Guangzhou 510060, China \\ ${ }^{4}$ Department of Pathology, Sun Yat-Sen University Cancer Center, State Key Laboratory of Oncology in South China, \\ Collaborative Innovation Center for Cancer Medicine, Guangzhou 510060, China \\ ${ }^{5}$ Department of Medical Oncology, Sun Yat-Sen Memorial Hospital, Sun Yat-Sen University, Guangzhou 510120, China \\ *These authors have contributed equally to this work \\ Correspondence to: \\ Li-kun Chen, e-mail: chenlk@sysucc.org.cn \\ Keywords: Non-small-cell lung cancer, brain metastasis, gefitinib, whole brain radiation therapy, blood brain barrier \\ Received: December 10,2014 Accepted: January 23, $2015 \quad$ Published: February 06, 2015
}

\section{ABSTRACT}

Introduction

To explore the ability of gefitinib to penetrate blood brain barrier (BBB) during whole brain radiation therapy (WBRT).

Patients and Methods

Enrolled in this study were eligible patients who were diagnosed with BM from NSCLC. Gefitinib was given at $250 \mathrm{mg} /$ day for $\mathbf{3 0}$ days, then concurrently with WBRT (40 Gy/20 F/4 w), followed by maintenance. Serial CSF and blood samples were collected on 30 day after gefitinib administration, and at the time of 10, 20, 30 and 40 Gy following WBRT. CSF and plasma samples of 13 patients without BM who were treated with gefitinib were collected as control. CSF and plasma gefitinib levels were measured by LC-MS/MS.

Results

Fifteen BM patients completed gefitinib plus WBRT. The CSF-to-plasma ratio of gefitinib in patients with $B M$ was higher than that in patients without BM $(1.34 \%$ vs. $0.36 \%, P<0.001)$. The CSF-to-plasma ratio of gefitinib increased with the increased dose of WBRT and reached the peak $(1.87 \pm 0.72 \%)$ at $30 \mathrm{~Gy}$, which was significantly higher than that $1.34 \pm 0.49 \%$ at $0 \mathrm{~Gy}(P=0.01)$. The median time to progression of brain lesions and the median overall survival were 7.07 and $\mathbf{1 5 . 4}$ months, respectively.

Conclusion

The BBB permeability of gefitinib increased in accordance with escalated dose of WBRT. 


\section{INTRODUCTION}

About $20-40 \%$ patients with non-small-cell lung cancer (NSCLC) develop brain metastasis (BM) [1-3]. The prognosis of BM from NSCLC is very poor with a median overall survival (OS) about 3-6 months in patients who received whole brain radiation therapy (WBRT). There are controversies over the role of systemic chemotherapy because of the limited ability of most potential agents to cross the blood-brain barrier (BBB) [4].

Studies [5] demonstrated that the integrity of BBB was disrupted in the presence of BM, and the BBB was leaky in a BM mouse model with tumors $>0.25 \mathrm{~mm}$. In addition, BM-related blood vessels were dilated and contained many dividing endothelial cells. Qin et al [6] reported the image intensity was $22 \%$ higher in brain tumor area than normal brain area by collecting Count/pixel data in ${ }^{99 \mathrm{M}} \mathrm{Tc}-$ GH imaging for a patient with BM which demonstrated the destructive effect of the BBB by brain tumor.

Epidermal growth factor receptor tyrosine kinase inhibitors (EGFR-TKIs) play an important treatment role for NSCLCpopulations worldwide. Gefitinib and erlotinib are oral EGFR-TKIs and have been approved in Asia for advanced NSCLC patients who have failed prior chemotherapy, or as first-line therapy for those with EGFR activating mutations [7-10]. Recently, gefitinib and erlotinib have been used for the treatment of patients with BM from NSCLC and reported effective against BM with a response rate (RR) of $10-58.3 \%$ and a disease control rate (DCR) of $22-77 \%$ in non-selected patients, bringing a median progression-free survival (PFS) of 3-9.7 months and a median OS of 8.3-18.9 months [11-17]. Whereas for patients harboring EGFR mutation, Park reported that the RR in brain was much higher as $83 \%$ [18]. Another study also reported the longer PFS for EGFR-mutated versus wide-type patients [19].

The role of EGFR-TKI with concurrent WBRT for NSCLC patients with BM is uncertain. A few studies showed that the combination of EGFR-TKI with concurrent WBRT has promising clinical activity. Ma et al [20] reported that the RR and DCR were $81 \%$ and $95 \%$ respectively in 21 NSCLC patients (EGFR non-selected) with BM treated by concurrent WBRT and gefitinib. Welsh et al [19] reported that the RR was $86 \%$ and the median OS was 11.8 months in patients treated with concurrent erlotinib and WBRT. There is no consensus regarding such treatment in NSCLC patients with BM. Future studies should focus on the role of EGFR-TKI with concurrent WBRT in patients with BM for more evidence.

Based on the efficacy of EGFR-TKIs, the cerebrospinal fluid (CSF) penetration of EGFR-TKIs is currently being investigated. Small-molecular-weight gefitinib may have the ability to penetrate the BBB [5,21-22]. Studies reported that the CSF penetration rates of gefitinib and erlotinib were about $1-1.3 \%$ and $2.77-7 \%$, respectively [22-29]. The CSF penetration rate of EGFR-TKI is relatively low.
Studies have found that BBB could be destroyed by radiation [21,30-31]. Some studies [6,32-34] reported that brain radiotherapy increased the penetration of anticancer drugs such as irinotecan, MTX and cisplatin into the CSF. Qin et al [33] reported that after irradiation of the brain with a dose of $20 \mathrm{~Gy}$ and intravenous administration of MTX to patients with brain tumors, the CSF-MTX concentration increased up to threefold. However, whether addition of WBRT could increase the permeability of gefitinib across the BBB remains unknown. In this prospective study, we evaluated the permeability of gefitinib across the BBB during WBRT in an attempt to obtain information about the efficacy and safety of gefitinib treatment with concurrent WBRT in NSCLC patients with BM.

\section{PATIENTS AND METHODS}

The study was approved by the medical ethics committee of Sun Yat-Sen University Cancer Center (Guangzhou, China). Written informed consent was obtained from all patients before initiation of the study.

\section{Patients}

The main inclusion criteria were pathologically confirmed NSCLC and clinically measurable brain metastases on magnetic resonance imaging (MRI) scans. Patients with 1-3 brain metastases were also eligible if they refused to receive neurosurgical or stereotactic radiosurgery (SRS).

Other eligibility criteria included age $\geq 18$ years, ECOG PS of $0-3$, a life expectancy $>3$ months, and evidence of adequate hematologic and hepatic function. All patients were pretreated with at least one line of chemotherapy regimens or chemotherapy-naïve patients with EGFR mutations.

The main exclusion criteria included prior WBRT for BM, prior EGFR inhibitor therapy, uncontrolled active infection or other serious concomitant disorders, pregnant patients and patients with mental disorders. Also, those who had significant neurologic symptoms or signs were excluded, but those with asymptomatic or controlled symptomatic brain metastases by corticosteroids or mannitol were included.

In addition, in order to compare the baseline gefitinib CSF levels in non-BM patients with that in BM patients before WBRT, the study enrolled 13 patients without BM as control. They were pathologically confirmed NSCLC and in the absence of BM by MRI. The patients were pretreated with at least one line of chemotherapy or chemotherapy-naïve patients with EGFR mutations and appropriate for gefitinib treatment.

\section{Treatment}

For NSCLC patients with BM, Gefitinib was administered orally at a daily dose of $250 \mathrm{mg}$ for 30 days, continued concurrently with WBRT (40 Gy/20 F) for 
4 weeks, and then maintained at the same dosage before occurrence of severe or intolerable toxicity, disease progression, or death. For NSCLC patients without BM, gefitinib was administered orally at a daily dose of 250 mg before occurrence of severe or intolerable toxicity, disease progression, or death. Tumor tissue specimens were collected to detect EGFR mutations by DNA direct sequencing. The study design is shown in Figure 1.

For patients with BM, serial CSF and blood samples were collected on day 30 after gefitinib administration before WBRT, and at the time of 10, 20, 30 and 40 Gy following WBRT. For patients without BM, blood and CSF samples only on day 30 after gefitinib administration were collected.

\section{Pharmacokinetic data}

Gefitinib as primary standard and vandetanib as internal standard were supplied by AstraZeneca.

\section{Blood and CSF sampling and detection of gefitinib levels}

Plasma and CSF concentrations of gefitinib were determined by a validated high-performance liquid chromatographic method (HPLC) with tandem mass spectrometric detection (LC/MS/MS), as described previously [35]. Plasma and CSF were isolated by centrifugation at $5000 \mathrm{rpm}$ at $4^{\circ} \mathrm{C}$ for $5 \mathrm{~min}$. Plasma and CSF analytes were extracted by liquid-liquid extraction using methyl tert-butyl ether (MTBE). Supernatants were evaporated to dryness and reconstituted with mobile phase. The samples were injected onto the liquid chromatography/ mass spectrometry (LC-MS) system, chromatographed with an Inertsil ODS3 column $(2.1 * 150 \mathrm{~mm} * 3 \mathrm{um})$ at $25^{\circ} \mathrm{C}$ column temperature, and detected using a PE Sciex API 2000 triple quadrupole mass spectrometer with a turbo ionspray source interfaced to an Agilent-1200 HPLC system. The mobile phase consisted of $0.02 \mathrm{M}$ ammonium acetateacetonitrile $(70: 30, \mathrm{v} / \mathrm{v}, \mathrm{pH}=3)$. The flow rate was set at $0.25 \mathrm{ml} / \mathrm{min}$, and all separations were carried out at $25^{\circ} \mathrm{C}$. The running time of each sample was $6 \mathrm{~min}$. Samples were quantified by the internal standard reference method in the MRM mode by monitoring the transition $\mathrm{m} / \mathrm{z} 447.2 \rightarrow 128.1$ for the analyte gefitinib and $\mathrm{m} / \mathrm{z} \quad 475.6 \rightarrow 112.0$ for the internal standard vandetanib. Standard curves were linear (r2 $>0.99$ ) over the range of $1-600 \mathrm{ng} / \mathrm{ml}$. The lower limit of quantification (LLOQ) of the method was $1 \mathrm{ng} / \mathrm{ml}$. The extraction recovery for vandetanib in plasma at $50 \mathrm{ng} / \mathrm{ml}$ was $80.62 \%$. For detection of gefitinib in plasma samples, the extraction recovery of gefitinib at 1, 3, 300, $480 \mathrm{ng} / \mathrm{ml}$ was found in the range of 74.47-84.52\%. The intra- and inter-batch precisions (RSD \%) and the intra- and interbatch accuracies were within $15 \%$.

\section{Efficacy and safety analyses}

Baseline assessment was performed within 2 weeks before gefitinib treatment, including medical history, physical examination, hematology and biochemistry test, chest CT and brain MRI. Chest CT scan and brain MRI were performed 30 days after gefitinib treatment and completion of WBRT, and then at 2-month intervals before death or loss to follow-up. Tumor response was evaluated according to the RECIST version 1.0 [36]. Toxicity evaluation was based on the National Cancer Institute Common Toxicity Criteria (NCICTC) version 3.0 and assessed monthly.

\section{Statistical methods}

PFS was calculated from the initiation of gefitinib administration to disease progression or death from any cause. Time to progression (TTP) was calculated from the initiation of gefitinib administration to disease progression. OS was calculated from the initiation of gefitinib administration to death from any cause. This study had an $90 \%$ power in order to detect a $1 \%$ higher in mean CSF-to-plasma ratio of gefitinib after WBRT compared with that before WBRT, with Standard deviation 1\% and $20 \%$ drop rate at a two-sided significance level of 0.05 . (see Supplementary Material File). Two independent sample $t$-test was used to determine difference of CSF-toplasma of gefitinib between BM and no BM. Paired sample $t$-test were used to determine the gefetinib concentration

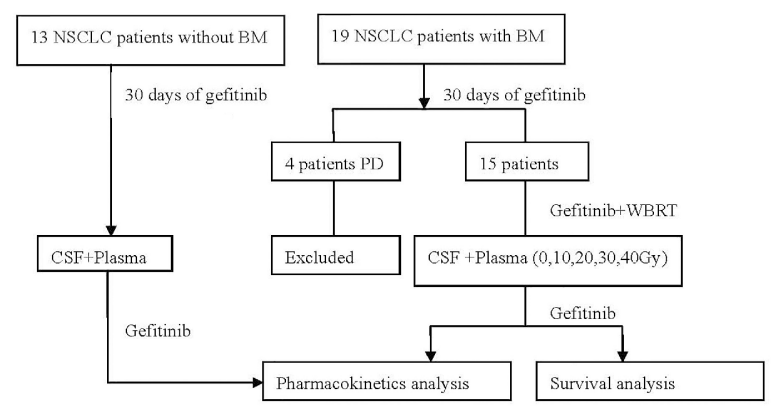

Figure 1: Disposition of patients (CONSORT diagram). 
of different durations. The relationships between CSF and serum concentrations of gefetinib were determined by linear regression. The survival curves were generated using the Kaplan-Meier method. Univariate analysis of patient characteristics and tumor responses was conducted by Pearson chi-square test or the Fisher exact test. Multivariate analysis was evaluated using a logistic regression model to predict the clinical response to the treatment regimen. The following variables were included: gender, age, performance status, smoking history, number and size of brain metastases, EGFR mutation status, and extracranial metastases. The Cox regression method was used to identify the most important independent prognostic factors and estimate the hazard ratio. All tests and confidence intervals (CIs) were two sided and a significance level was 0.05 . Statistical analyses were performed by using SPSS software, Version 13.0.

\section{RESULTS}

\section{Baseline characteristics}

From October 2009 to March 2011, 19 NSCLC patients with BM were enrolled, of whom four patients progressed 30 days after gefitinib treatment, and the remaining 15 patients received gefitinib with concurrent WBRT. The baseline characteristics of these 15 patients are listed in Table 1. All the 15 patients underwent EGFR testing, finding 6 patients who had EGFR mutations, including 5 exon 19 deletions and 1 exon 21 L858R point mutations.

\section{Pharmacokinetic results}

Samples from the 13 patients without BM and the 15 patients with BM were collected and analyzed.

The plasma concentrations of gefitinib were similar between patients with and without BM. Both the mean CSF concentration of gefitinib and the CSF-to-plasma ratio of gefitinib in patients with BM were significantly higher than those in patients without BM (Table 2, $P<0.001$ ). A good correlation $\left(\mathrm{R}^{2}=0.57\right)$ between plasma and CSF concentrations of gefitinib in 15 patients with BM before WBRT was demonstrated ( $P=0.001$, Figure $2 \mathrm{~A})$. Similarly, a good correlation $\left(\mathrm{R}^{2}=0.70\right)$ between plasma and CSF concentrations of gefitinib was demonstrated in 13 patients without $\mathrm{BM}(P=0.004$, Figure $2 \mathrm{~B})$. The CSF concentration of gefitinib and the CSF-to-plasma ratio increased with escalation of the WBRT dose (Figure 3A, 3B). The mean CSF concentration of gefitinib at 30 and 40 Gy was statistically higher than that at $0 \mathrm{~Gy}$. The CSF-to-plasma ratio of gefitinib reached the peak $(1.87 \pm 0.72 \%)$ at $30 \mathrm{~Gy}$, which was significantly higher than $1.34 \pm 0.49 \%$ at 0 Gy $(P=0.01)$. Pharmacokinetic analysis indicated that the addition of WBRT enhanced gefitinib's ability of penetration in CSF.

The mean CSF concentration of gefitinib at 20-40 Gy (4.85-5.82 ng/ml) reached IC50 (4.46-8.9 ng/mL /10 $20 \mathrm{nM} / \mathrm{L})$ for EGFR mutant NSCLC cell lines [37].
The number (single $v s$. multiple) and size $(\leq 20 \mathrm{~mm}$ $v s .>20 \mathrm{~mm}$ ) of brain lesions did not significantly affect the permeability of gefitinib in patients with BM from NSCLC. The EGFR mutation status was not related to the permeability of the BBB to gefitinib.

\section{Efficacy outcomes}

Five patients treated with gefitinib and concurrent WBRT were alive at the time of this analysis, and the median follow-up time was 15.4 months (range 4.1-28.23 months). The median PFS and OS were 6.17 and 15.40 months, respectively. The median TTP for intracranial and lung lesions were both 7.07 months. Tumor responses of extracranial lesions and brain metastases were similar (Table 3 ).

The treatment response and survival analysis of the 15 patients according to the EGFR mutation status were shown in Table 3. The median PFS and OS in patients with EGFR mutations were significantly longer, compared with patients with EGFR wild type $(P<0.05$, Figure 4A, 4B). The median TTP of either brain lesions or primary lung lesions was significantly longer in EGFR mutant patients $(P<0.05)$ (Figure 4C, 4D). In addition, the RR of BM was higher in patients with EGFR mutant disease than that in patients with wild-type disease (83.33\% vs.11.11\%) (Table 4).

\section{Toxicity and safety}

All 15 patients were included in the toxicity analysis. The reported adverse events (AEs) are summarized in Table 5. The most common AEs reported were rash $(53.3 \%, 8 / 15)$ outside the radiation field, acne $(33.3 \%$, $5 / 15)$, radiation field dermatitis $(20 \%, 3 / 15)$, paronychia $(20 \%, 3 / 15)$, pruritus $(20 \%, 3 / 15)$, fatigue $(26.7 \%, 4 / 15)$, diarrhea $(33.3 \%, 5 / 15)$, and vomiting $(20 \%, 3 / 15)$. We saw no cases of radiation enhancing the gefitinib-related rash in the portal treatment area. All toxicities were grade 1 or 2 . The reported neurotoxicities during the combined treatment were headache $(20 \%)$, dizziness $(6.7 \%)$, memory impairment (6.7\%), and hydrocephalus (6.7\%). We saw no cases of leukoencephalopathy and cognitive disturbance. No statistically significant differences were found between gefitinib-WBRT group and the historical WBRT group in the proportion of patients with evidence of neurotoxicity. Patients had no treatment related ocular symptoms.

\section{DISCUSSION}

Brain metastases are associated with poor prognosis, for which there is no effective treatment at present. WBRT is a standard treatment for BM. The low CSF penetration of chemotherapeutic drugs remains a significant factor contributing to poor therapeutic outcomes for BM patients. Small-molecular-weight (446.9 daltons) gefitinib may have the ability to penetrate the $\operatorname{BBB}[5,21-22]$. Some studies [21] reported that BM and WBRT could disrupt the 
Table 1: Patient characteristics $(n=15)$

\begin{tabular}{|c|c|c|}
\hline Characteristics & $N$ & $\%$ \\
\hline \multicolumn{3}{|l|}{ Age (yrs) } \\
\hline Median (yrs) & 52 & \\
\hline Range (yrs) & $20-72$ & \\
\hline$\leq 65$ & 14 & 93.33 \\
\hline$>65$ & 1 & 6.67 \\
\hline \multicolumn{3}{|l|}{ Gender } \\
\hline Male & 7 & 46.67 \\
\hline Female & 8 & 53.33 \\
\hline \multicolumn{3}{|l|}{ Pathology } \\
\hline Adenocarcinoma & 13 & 86.67 \\
\hline Adenosquamous carcinoma & 2 & 13.33 \\
\hline \multicolumn{3}{|l|}{ Performance status } \\
\hline $0-2$ & 13 & 86.67 \\
\hline 3 & 2 & 13.33 \\
\hline \multicolumn{3}{|l|}{ Smoking } \\
\hline Never or light smoker & 9 & 60 \\
\hline Heavy smoker & 6 & 40 \\
\hline \multicolumn{3}{|l|}{ Initial diagnosis of BM } \\
\hline Yes & 7 & 46.67 \\
\hline No & 8 & 53.33 \\
\hline \multicolumn{3}{|l|}{ No. of brain metastases } \\
\hline Single & 6 & 40 \\
\hline Multiple & 9 & 60 \\
\hline \multicolumn{3}{|l|}{ Size of brain metastases $(\mathrm{mm})$} \\
\hline$\leq 20$ & 14 & 93.33 \\
\hline$>20$ & 1 & 6.67 \\
\hline \multicolumn{3}{|l|}{ CNS symptoms } \\
\hline Yes & 5 & 33.33 \\
\hline No & 10 & 66.67 \\
\hline \multicolumn{3}{|l|}{ EGFR mutations } \\
\hline Negative & 9 & 60 \\
\hline Positive & 6 & 40 \\
\hline \multicolumn{3}{|l|}{ Organs of extracranial metastases } \\
\hline Yes & 12 & 80 \\
\hline No & 3 & 20 \\
\hline \multicolumn{3}{|l|}{ No.of prior chemotherapy } \\
\hline 0 & 3 & 20 \\
\hline 1 & 6 & 40 \\
\hline$\geq 2$ & 6 & 40 \\
\hline
\end{tabular}




\begin{tabular}{l}
\hline Characteristics \\
\begin{tabular}{|l|c|c|}
\hline Prior thoracic irradiation & 3 & $\%$ \\
\hline Yes & 12 & 20 \\
\hline No & & 80 \\
\hline RPA grouping & 5 & 33.33 \\
\hline 1 & 9 & 60 \\
\hline 2 & 1 & 6.67 \\
\hline 3 & 1 & 6.67 \\
\hline Prior stereotactic radiosurgery & 1 & \\
\hline
\end{tabular}
\end{tabular}

Abbreviation: BM, brain metastasis; CNS, central neurology system; EGFR, epidermal growth factor receptor; RPA, recursive partitioning analysis.

Table 2: The comparison of gefitinib concentration in CSF and blood between patients with BM before WBRT and patients without BM

\begin{tabular}{|l|c|c|c|}
\cline { 2 - 3 } \multicolumn{1}{c}{ Body fluid } & \multicolumn{2}{c}{ Concentration $(\mathbf{n g} / \mathbf{m l})$} & \multirow{2}{c}{ Pvalue } \\
\hline CSF & $1.41 \pm 0.7$ & $4.15 \pm 1.72$ & $<0.001$ \\
\hline Blood & $366.54 \pm 106.44$ & $321.87 \pm 134.60$ & 0.344 \\
\hline Ratio (\%) & $0.36 \pm 0.18$ & $1.34 \pm 0.49$ & $<0.001$ \\
\hline
\end{tabular}

Abbreviation: CSF: cerebrospinal fluid; BM, brain metastases
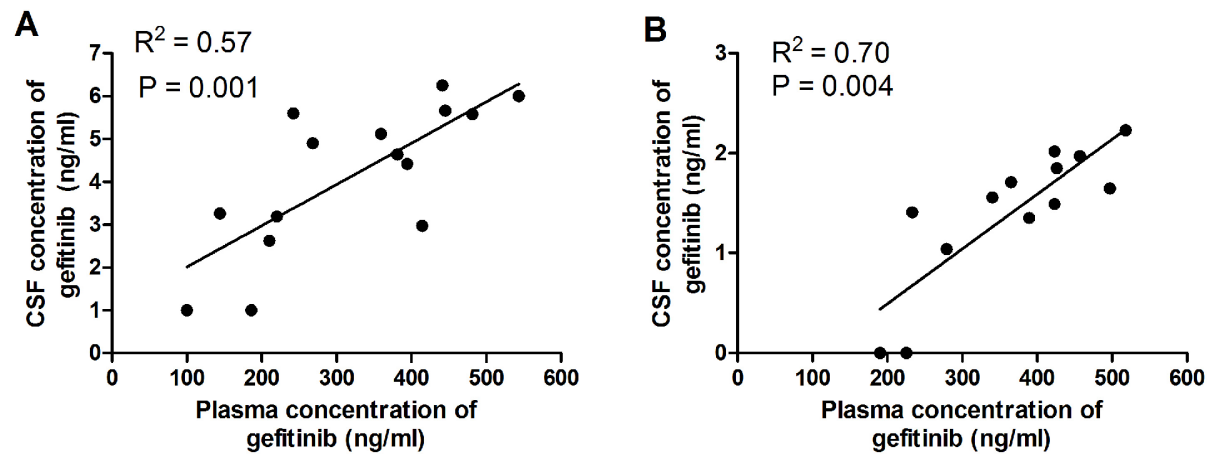

Figure 2: (A) Correlation between plasma and CSF concentrations of gefitinib in 15 patients with BM. A good correlation $\left(\mathrm{R}^{2}=0.57\right)$ was demonstrated $(P=0.001)$. (B) Correlation between plasma and CSF concentrations of gefitinib in 13 patients without BM. A good correlation $\left(\mathrm{R}^{2}=0.70\right)$ was demonstrated $(P=0.004)$.

BBB. To the best of our knowledge, the effect of WBRT on gefitinib permeability across the BBB has not been previously reported. The major objective of our study was to evaluate whether WBRT could affect BBB permeability of gefitinib in BM patients.

For years, brain metastasis has been considered to increase the permeability of the BBB [38]. Our study presented evidence that gefitinib could only reach a rather low level in patients without BM, with a CSF-to-plasma gefitinib ratio about $0.36 \% \pm 0.18 \%$. Our study showed that CSF level of gefitinib was $4.15 \mathrm{ng} / \mathrm{ml}$ and the CSF-toplasma ratio of gefitinib before WBRT was only $1.34 \%$, which is similar to that reported in other studies [22-24, 39]. The CSF-to-plasma gefitinib ratio in patients with BM before WBRT was significantly higher than that in patients without BM. Although BM could disrupt the BBB, the CSF penetration ability of gefitinib remains low.

WBRT can disrupt the BBB. d'Avella et al [30, 32] reported that WBRT (40 Gy/20 F) induced changes in BBB function with the significant increase of transport 


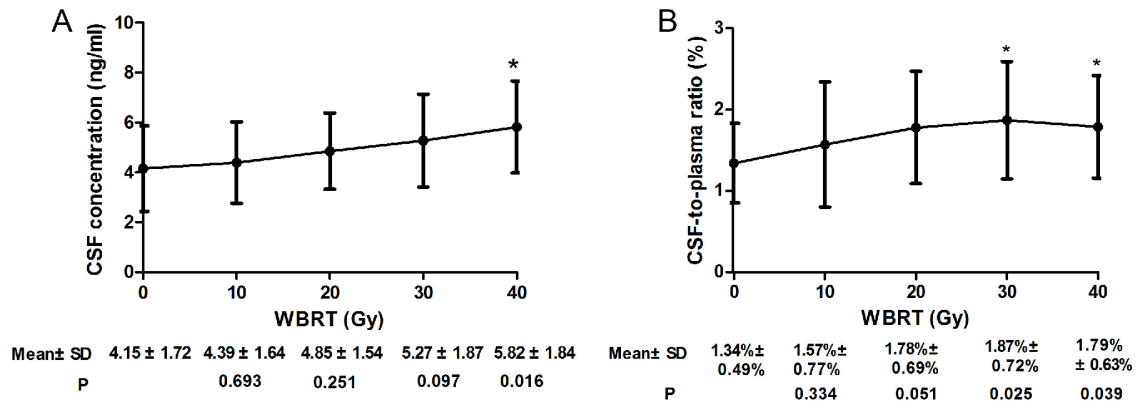

Figure 3: Gefitinib CSF concentration (A) and CSF-to-plasma ratio of gefitinib concentration (B) during WBRT compared with that of baseline ( 0 Gy). ${ }^{*} P<0.05$.

Table 3: Response and survival of 15 patients with BM from NSCLC treated by gefitinib plus WBRT

\begin{tabular}{|c|c|c|}
\hline & $N$ & $\%$ \\
\hline \multicolumn{3}{|l|}{ Brain metastases } \\
\hline $\mathrm{RR}(\%)$ & 6 & 40 \\
\hline DCR $(\%)$ & 13 & 86.67 \\
\hline TTP (months) & 7.07(95\%CI:3.24-10.90) & \\
\hline \multicolumn{3}{|l|}{ Primary thoracic lesions } \\
\hline $\mathrm{RR}(\%)$ & 6 & 40 \\
\hline $\operatorname{DCR}(\%)$ & 12 & 80 \\
\hline Median TTP (months) & 7.07(95\%CI:2.14-11.99) & \\
\hline \multicolumn{3}{|l|}{ Overall } \\
\hline $\mathrm{RR}(\%)$ & 6 & 40 \\
\hline $\operatorname{DCR}(\%)$ & 12 & 80 \\
\hline Median PFS (months) & 6.17 (95\%CI:1.50-10.84) & \\
\hline Median OS (months) & 15.40 (95\%CI:11.33-19.47) & \\
\hline Rate at $1-y r(\%)$ & & 66.6 \\
\hline Rate at 2-yr (\%) & & 38.9 \\
\hline
\end{tabular}

Abbreviation: BM, brain metastasis; WBRT, whole brain radiation therapy; RR: response rate; DCR: disease control rate; TTP, time to progression; PFS: progression-free survival; OS: overall survival; 95\%CI, 95\% confidential internal.

of ${ }^{14} \mathrm{C}$-alpha-aminoisobutyric acid across the $\mathrm{BBB}$ in the cerebral cortex 15 days after WBRT. Qin et al $[6,33]$ observed that radiotherapy enhanced the destruction of the $\mathrm{BBB}$ and the degree of the destructive effect on the $\mathrm{BBB}$ in the irradiated normal area directly proportional to the radiation dose, and the ratio of MTX concentration in blood and CSF increased by 1.43 fold after 40 Gy WBRT. Some studies [33-34] reported that brain radiation could increase the penetration of anticancer drugs such as irinotecan and cisplatin into the CSF. However, there are no current data to support the effect of WBRT on gefitinib permeability across the BBB in patients with BM from advanced NSCLC. Our study also showed that the
CSF-to-plasma ratio of gefitinib increased with the increased dose of WBRT and reached the peak $(1.87 \pm$ $0.72 \%$ ) at $30 \mathrm{~Gy}$, which is significantly higher than 1.34 $\pm 0.49 \%$ at 0 Gy $(P=0.01)$. In addition, Gow et al [40] reported that the administration of EGFR TKI during WBRT conferred radiosensitivity in brain metastasis of lung adenocarcinoma. WBRT may enhance the efficacy of gefitinib for BM patients.

The mean CSF concentration of gefitinib at 20-40 Gy was $4.85-5.82 \mathrm{ng} / \mathrm{mL}$, reaching the IC50 of gefitinib in vitro of EGFR-mutant cell lines [37]. This may explain the high disease control of brain lesions (RR 83.33\%; DCR $100 \%$ ) in EGFR mutant patients with BM. Therefore, 

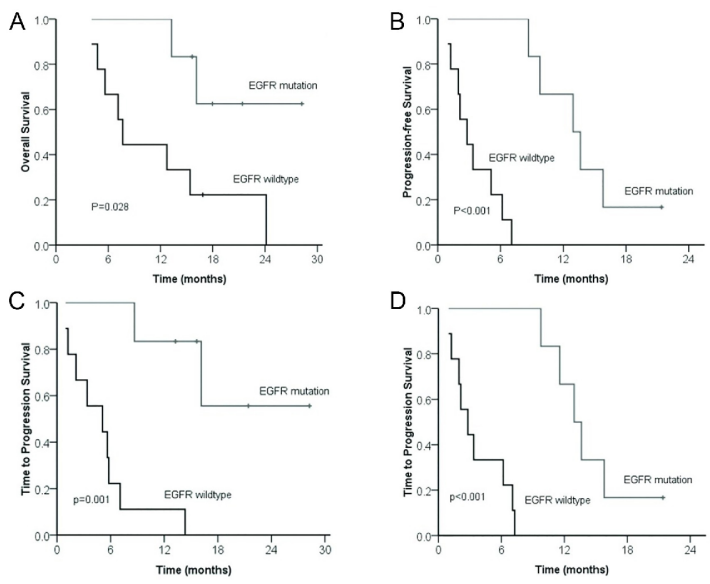

Figure 4: Comparison of overall survival (A) and progression-free survival (B) between patients with BM from NSCLC according to EGFR mutation status. Comparison of time to progression of brain lesions (C) and lung lesions (D) from patients with BM from NSCLC according to EGFR mutation status.

Table 4: Treatment response of patients with BM from NSCLC treated by gefitinib plus WBRT according to EGFR mutation status

\begin{tabular}{|c|c|c|c|}
\hline \multirow[t]{2}{*}{ Response } & \multicolumn{2}{|c|}{ EGFR } & \multirow[t]{2}{*}{$P$ value } \\
\hline & Wild-type $(n=9)$ & Mutant $(n=6)$ & \\
\hline \multicolumn{4}{|l|}{ Brain metastases } \\
\hline RR (\%) & $1(11.11 \%)$ & $5(83.33 \%)$ & 0.01 \\
\hline $\operatorname{DCR}(\%)$ & $7(77.78 \%)$ & $6(100 \%)$ & 0.49 \\
\hline Median TTP (months) & 5.10(95\%CI: $0.04-10.16)$ & - & 0.001 \\
\hline \multicolumn{4}{|l|}{ Primary thoracic lesions } \\
\hline RR (\%) & $1(11.11 \%)$ & $5(83.33 \%)$ & 0.01 \\
\hline $\operatorname{DCR}(\%)$ & $6(66.67 \%)$ & $6(100 \%)$ & 0.23 \\
\hline Median TTP (months) & 2.80(95\%CI:0.85-4.74) & 12.93(95\%CI:10.45-15.41) & $<0.001$ \\
\hline \multicolumn{4}{|l|}{ Overall } \\
\hline RR (\%) & $1(11.1 \%)$ & $5(83.33 \%)$ & 0.01 \\
\hline $\operatorname{DCR}(\%)$ & $6(66.7 \%)$ & $6(100 \%)$ & 0.23 \\
\hline Median OS (months) & 7.67(95\%CI: 6.11-9.23) & - & 0.03 \\
\hline Median PFS (months) & $2.80(95 \%$ CI: 0.85-4.75) & 12.93(95\%CI:8.29-17.57) & $<0.001$ \\
\hline
\end{tabular}

Abbreviation: BM, brain metastasis; WBRT, whole brain radiation therapy; RR: response rate; DCR: disease control rate; TTP, time to progression; OS: overall survival; PFS: progression-free survival; 95\% CI, 95\% confidential internal; — : not yet reached.

BM patients with EGFR mutations could benefit more from gefitinib. In addition, we also found that the CSF concentration of gefitinib was well correlated with its plasma concentration. Some studies $[22,41]$ reported that administration of high-dose EGFR-TKIs could achieve a higher CSF concentration and clinical efficacy as compared with standard dosing. One study [22] reported that the CSF concentration of gefitinib increased with the increased dose of gefitinib, ranged from 6.2 to $18 \mathrm{nM}$ at a 500-mg dose, and reached $42 \mathrm{nM}$ at a 1,000-mg dose in patients with leptomeningeal metastasis. Clarke et al [41] reported that patients with NSCLC leptomeningeal metastases treated with $1500 \mathrm{mg}$ erlotinib weekly demonstrated a peak plasma concentration of $11,300 \mathrm{nM}$ with a concurrent CSF concentration of $130 \mathrm{nM}$ exceeding the IC50. Therefore, high-dose pulsatile EGFR-TKIs may be an alternative 
Table 5: Treatment-related toxicities during gefitinib with concurrent WBRT

\begin{tabular}{|l|c|c|c|}
\hline Adverse event & Grade $\mathbf{1 / 2}, \boldsymbol{n}$ & Grade 3/4, & Total, $\boldsymbol{n}$ (\%) \\
\hline Rash & 8 & 0 & $8(53.3)$ \\
\hline Acne & 5 & 0 & $5(33.3)$ \\
\hline Radiation dermatitis & 3 & 0 & $3(20)$ \\
\hline Dry skin & 2 & 0 & $2(13.3)$ \\
\hline Pruritus & 3 & 0 & $3(20)$ \\
\hline Paronychia & 3 & 0 & $3(20)$ \\
\hline Vomiting & 3 & 0 & $3(20)$ \\
\hline Diarrhea & 5 & 0 & $5(33.3)$ \\
\hline Fatigue & 4 & 0 & $4(26.7)$ \\
\hline ALT elevation & 1 & 0 & $1(6.7)$ \\
\hline Pneumonia & 0 & 0 & 0 \\
\hline Headache & 3 & 0 & $3(20)$ \\
\hline Cognitive disturbance & 0 & 0 & 0 \\
\hline Confusion & 0 & 0 & 0 \\
\hline Dizziness & 1 & 0 & $1(6.7)$ \\
\hline Hydrocephalus & 1 & 0 & $1(6.7)$ \\
\hline Leukoencephalopathy & 0 & 0 & 0 \\
\hline Memory impairment & 1 & 0 & $1(6.7)$ \\
\hline Seizure & 0 & 0 & 0 \\
\hline
\end{tabular}

strategy to treat central nervous system (CNS) metastases from NSCLC with EGFR wild-type. Grommes et al [42] reported that pulsatile erlotinob at approximately $1500 \mathrm{mg}$ per week was safe and had activity in patients with CNS diseases from EGFR mutant NSCLC even when systemic resistance had developed and been confirmed.

Our study showed that penetration of gefitinib into CSF was facilitated under the condition of BM- and WBRTinduced BBB disruption, which supports the beneficial effect of using gefitinib with concurrent WBRT in patients with BM. However, previous studies on the efficacy of EGFRTKIs with concurrent WBRT have yielded conflicting results. Pesce et al [43] reported that the median OS in their 16 patients with BM treated with gefitinib and concurrent WBRT was 6.3 months, showing no clinical benefit compared with historical controls receiving gefitinib alone [12, 14, 17, 44]. Welsh et al [19] reported that in their 40 patients treated with erlotinib plus WBRT, the median OS for those with EGFR wild type and EGFR mutations were 9.3 and 19.1 months, respectively. Despite clinically significant findings, it still has some limitations. The relatively small number of patients recruited should be considered when interpreting the results. In addition, EGFR status was confirmed using samples from lung lesions and not with intracranial lesions. Further studies are needed to confirm the clinical benefit of EGFR-TKIs and concurrent WBRT in patients with BM.

Pharmacokinetically, our study supports the combination of EGFR-TKIs with concurrent WBRT in treating patients with $\mathrm{BM}$, especially for patients with activating EGFR mutations. Further studies could be made to compare concurrent and sequential therapy of gefitinib and WBRT. It remains unknown whether EGFR-TKI with concurrent WBRT is superior to EGFR-TKI alone in NSCLC with BM, especially for patients with activating EGFR mutations. In addition, CSF level of gefitinib may not be the same as that in patients with brain lesions, and disruption of the BBB in BM may be more severe than that in the surrounding tissues. It seems more reasonable to study the drug concentration within the brain tumor in study of CNS pharmacokinetics of anticancer therapies.

\section{ACKNOWLEDGMENTS}

The authors would like to thank the patients for their trust and participation. This study was supported in part by a grant from the $\mathrm{Wu}$ Jieping Medical Foundation of China (No. 320.6700.09040). 


\section{DISCLOSURE OF CONFLICT OF INTEREST}

The authors declare no conflicts of interest.

\section{REFERENCES}

1. Rizzi A, Tondini M, Rocco G, Rossi G, Robustellini M, Radaelli F, Della Pona C. Lung cancer with a single brain metastasis: therapeutic options. Tumori. 1990; 76:579-581.

2. Yawn BP, Wollan PC, Schroeder C, Gazzuola L, Mehta M. Temporal and gender-related trends in brain metastases from lung and breast cancer. Minn Med. 2003; 86:32-37.

3. Olak J. Surgical strategies for metastatic lung cancer. Surg Oncol Clin N Am. 1999; 8:245-257.

4. Grimm SA. Treatment of brain metastases: chemotherapy. Curr Oncol Rep. 2012; 14:85-90.

5. Fidler IJ, Yano S, Zhang RD, Fujimaki T, Bucana CD. The seed and soil hypothesis: vascularisation and brain metastases. Lancet Oncol. 2002; 3:53-57.

6. Qin DX, Zheng R, Tang J, Li JX, Hu YH. Influence of radiation on the blood-brain barrier and optimum time of chemotherapy. Int J Radiat Oncol Biol Phys. 1990; 19:1507-1510.

7. Shepherd FA, Rodrigues Pereira J, Ciuleanu T, Tan EH, Hirsh V, Thongprasert S, Campos D, Maoleekoonpiroj S, Smylie M, Martins R, van Kooten M, Dediu M, Findlay B, Tu D, Johnston D, Bezjak A, et al. Erlotinib in previously treated non-small-cell lung cancer. N Engl J Med. 2005; 353:123-132.

8. Thatcher N, Chang A, Parikh P, Rodrigues Pereira J, Ciuleanu $\mathrm{T}$, von Pawel J, Thongprasert S, Tan EH, Pemberton K, Archer V, Carroll K. Gefitinib plus best supportive care in previously treated patients with refractory advanced non-small-cell lung cancer: results from a randomised, placebo-controlled, multicentre study (Iressa Survival Evaluation in Lung Cancer)Lancet. 2005; 366:1527-1537.

9. Kim ES, Hirsh V, Mok T, Socinski MA, Gervais R, Wu YL, Li LY, Watkins CL, Sellers MV, Lowe ES, Sun Y, Liao ML, Osterlind K, Reck M, Armour AA, Shepherd FA, et al. Gefitinib versus docetaxel in previously treated non-smallcell lung cancer (INTEREST): a randomised phase III trial. Lancet. 2008; 372:1809-1818.

10. Mok TS, Wu YL, Thongprasert S, Yang CH, Chu DT, Saijo N, Sunpaweravong P, Han B, Margono B, Ichinose Y, Nishiwaki Y, Ohe Y, Yang JJ, Chewaskulyong B, Jiang H, Duffield EL, et al. Gefitinib or carboplatin-paclitaxel in pulmonary adenocarcinoma. N Engl J Med. 2009; 361:947-957.

11. Heimberger AB, Learn CA, Archer GE, McLendon RE, Chewning TA, Tuck FL, Pracyk JB, Friedman AH, Friedman HS, Bigner DD, Sampson JH. Brain tumors in mice are susceptible to blockade of epidermal growth factor receptor (EGFR) with the oral, specific, EGFR-tyrosine kinase inhibitor ZD1839 (iressa). Clin Cancer Res. 2002; 8:3496-3502.

12. Wu C, Li YL, Wang ZM, Li Z, Zhang TX, Wei Z. Gefitinib as palliative therapy for lung adenocarcinoma metastatic to the brain. Lung Cancer. 2007; 57:359-364.

13. Hotta K, Kiura K, Ueoka H, Tabata M, Fujiwara K, Kozuki T, Okada T, Hisamoto A, Tanimoto M. Effect of gefitinib ('Iressa', ZD1839) on brain metastases in patients with advanced non-small-cell lung cancer. Lung Cancer. 2004; 46:255-261.

14. Namba Y, Kijima T, Yokota S, Niinaka M, Kawamura S, Iwasaki T, Takeda Y, Kimura H, Okada T, Yamaguchi T, Nakagawa M, Okumura Y, Maeda H, Ito M. Gefitinib in patients with brain metastases from non-small-cell lung cancer: review of 15 clinical cases. Clin Lung Cancer. 2004; 6:123-128.

15. Takahashi H, Ohrui T, Ebihara S, Yamada M, Sasaki H. Effect of gefitinib (ZD1839) on metastatic brain tumour. Lung Cancer. 2004; 43:371-372.

16. Shimato S, Mitsudomi T, Kosaka T, Yatabe $\mathrm{Y}$, Wakabayashi T, Mizuno M, Nakahara N, Hatano H, Natsume A, Ishii D, Yoshida J. EGFR mutations in patients with brain metastases from lung cancer: association with the efficacy of gefitinib. Neuro Oncol. 2006; 8:137-144.

17. Ceresoli GL, Cappuzzo F, Gregorc V, Bartolini S, Crino L, Villa E. Gefitinib in patients with brain metastases from non-small-cell lung cancer: a prospective trial. Ann Oncol. 2004; 15:1042-1047.

18. Park SJ, Kim HT, Lee DH, Kim KP, Kim SW, Suh C, Lee JS. Efficacy of epidermal growth factor receptor tyrosine kinase inhibitors for brain metastasis in non-small cell lung cancer patients harboring either exon 19 or 21 mutation. Lung Cancer. 2012; 77:556-560.

19. Welsh JW, Komaki R, Amini A, Munsell MF, Unger W, Allen PK, Chang JY, Wefel JS, McGovern SL, Garland LL, Chen SS, Holt J, Liao Z, Brown P, Sulman E, Heymach JV, et al. Phase II Trial of Erlotinib Plus Concurrent Whole-Brain Radiation Therapy for Patients With Brain Metastases From Non-Small-Cell Lung Cancer. J Clin Oncol. 2013: 31:895-902.

20. Ma SL, Xu YP, Deng QH, Yu XM. Treatment of brain metastasis from non-small cell lung cancer with whole brain radiotherapy and Gefitinib in a Chinese population. Lung Cancer. 2009; 65:198-203.

21. van Vulpen M, Kal HB, Taphoorn MJ, El-Sharouni SY. Changes in blood-brain barrier permeability induced by radiotherapy: implications for timing of chemotherapy? (Review). Oncol Rep. 2002; 9:683-688.

22. Jackman DM, Holmes AJ, Lindeman N, Wen PY, Kesari S, Borras AM, Bailey C, de Jong F, Janne PA, Johnson BE. Response and resistance in a non-small-cell lung cancer patient with an epidermal growth factor receptor mutation and leptomeningeal metastases treated with high-dose gefitinib. J Clin Oncol. 2006; 24:4517-4520.

23. Fukuhara T, Saijo Y, Sakakibara T, Inoue A, Morikawa N, Kanamori M, Nakashima I, Nukiwa T. Successful treatment 
of carcinomatous meningitis with gefitinib in a patient with lung adenocarcinoma harboring a mutated EGF receptor gene. Tohoku J Exp Med. 2008; 214:359-363.

24. Zhao J, Chen M, Zhong W, Zhang L, Li L, Xiao Y, Nie L, $\mathrm{Hu}$ P, Wang M. Cerebrospinal fluid concentrations of gefitinib in patients with lung adenocarcinoma. Clin Lung Cancer. 2013; 14:188-193.

25. Togashi Y, Masago K, Masuda S, Mizuno T, Fukudo M, Ikemi Y, Sakamori Y, Nagai H, Kim YH, Katsura T, Mishima M. Cerebrospinal fluid concentration of gefitinib and erlotinib in patients with non-small cell lung cancer. Cancer Chemother Pharmacol. 2012; 70:399-405.

26. Togashi Y, Masago K, Fukudo M, Terada T, Fujita S, Irisa K, Sakamori Y, Kim YH, Mio T, Inui K, Mishima M. Cerebrospinal fluid concentration of erlotinib and its active metabolite OSI-420 in patients with central nervous system metastases of non-small cell lung cancer. J Thorac Oncol. 2010; 5:950-955.

27. Masuda T, Hattori N, Hamada A, Iwamoto H, Ohshimo S, Kanehara M, Ishikawa N, Fujitaka K, Haruta Y, Murai H, Kohno N. Erlotinib efficacy and cerebrospinal fluid concentration in patients with lung adenocarcinoma developing leptomeningeal metastases during gefitinib therapy. Cancer Chemother Pharmacol. 2011; 67:1465-1469.

28. Broniscer A, Panetta JC, O’Shaughnessy M, Fraga C, Bai F, Krasin MJ, Gajjar A, Stewart CF. Plasma and cerebrospinal fluid pharmacokinetics of erlotinib and its active metabolite OSI-420. Clin Cancer Res. 2007; 13:1511-1515.

29. Deng Y, Feng W, Wu J, Chen Z, Tang Y, Zhang H, Liang J, Xian H, Zhang S. The concentration of erlotinib in the cerebrospinal fluid of patients with brain metastasis from nonsmall-cell lung cancer. Mol Clin Oncol. 2014; 2:116-120.

30. d'Avella D, Cicciarello R, Angileri FF, Lucerna S, La Torre D, Tomasello F. Radiation-induced blood-brain barrier changes: pathophysiological mechanisms and clinical implications. Acta Neurochir Suppl. 1998; 71:282-284.

31. Qin D, Zheng R, Ma J, Xiao J, Tang Z. Influence of radiation on the blood-brain barrier and optimum time of chemotherapy. Zhongguo Yi Xue Ke Xue Yuan Xue Bao. 1999; 21:307-310.

32. d'Avella D, Cicciarello R, Albiero F, Mesiti M, Gagliardi ME, Russi E, d'Aquino A, Tomasello F, d'Aquino S. Quantitative study of blood-brain barrier permeability changes after experimental whole-brain radiation. Neurosurgery. 1992; 30:30-34.

33. Qin D, Ma J, Xiao J, Tang Z. Effect of brain irradiation on blood-CSF barrier permeability of chemotherapeutic agents. Am J Clin Oncol. 1997; 20:263-265.

34. Khatri A, Gaber MW, Brundage RC, Naimark MD, Hanna SK, Stewart CF, Kirstein MN. Effect of radiation on the penetration of irinotecan in rat cerebrospinal fluid. Cancer Chemother Pharmacol. 2011; 68:721-731.

35. Jones HK, Stafford LE, Swaisland HC, Payne R. A sensitive assay for ZD1839 (Iressa) in human plasma by liquid-liquid extraction and high performance liquid chromatography with mass spectrometric detection: validation and use in Phase I clinical trials. J Pharm Biomed Anal. 2002; 29:221-228.

36. Therasse P, Arbuck SG, Eisenhauer EA, Wanders J, Kaplan RS, Rubinstein L, Verweij J, Van Glabbeke M, van Oosterom AT, Christian MC, Gwyther SG. New guidelines to evaluate the response to treatment in solid tumors. European Organization for Research and Treatment of Cancer, National Cancer Institute of the United States, National Cancer Institute of Canada. J Natl Cancer Inst. 2000; 92:205-216.

37. Mukohara T, Engelman JA, Hanna NH, Yeap BY, Kobayashi S, Lindeman N, Halmos B, Pearlberg J, Tsuchihashi Z, Cantley LC, Tenen DG, Johnson BE, Janne PA. Differential effects of gefitinib and cetuximab on non-small-cell lung cancers bearing epidermal growth factor receptor mutations. J Natl Cancer I. 2005; 97:1185-1194.

38. Wilson CM, Gaber MW, Sabek OM, Zawaski JA, Merchant TE. Radiation-induced astrogliosis and bloodbrain barrier damage can be abrogated using anti-TNF treatment. Int J Radiat Oncol Biol Phys. 2009; 74:934-941.

39. Lassman AB, Rossi MR, Raizer JJ, Abrey LE, Lieberman FS, Grefe CN, Lamborn K, Pao W, Shih AH, Kuhn JG, Wilson R, Nowak NJ, Cowell JK, DeAngelis LM, Wen P, Gilbert MR, et al. Molecular study of malignant gliomas treated with epidermal growth factor receptor inhibitors: tissue analysis from North American Brain Tumor Consortium Trials 01-03 and 00-01. Clin Cancer Res. 2005; 11:7841-7850.

40. Gow CH, Chien CR, Chang YL, Chiu YH, Kuo SH, Shih JY, Chang YC, Yu CJ, Yang CH, Yang PC. Radiotherapy in lung adenocarcinoma with brain metastases: Effects of activating epidermal growth factor receptor mutations on clinical response. Clin Cancer Res. 2008; 14:162-168.

41. Clarke JL, Pao W, Wu N, Miller VA, Lassman AB. High dose weekly erlotinib achieves therapeutic concentrations in CSF and is effective in leptomeningeal metastases from epidermal growth factor receptor mutant lung cancer. J Neurooncol. 2010; 99:283-286.

42. Grommes C, Oxnard GR, Kris MG, Miller VA, Pao W, Holodny AI, Clarke JL, Lassman AB. "Pulsatile" high-dose weekly erlotinib for CNS metastases from EGFR mutant nonsmall cell lung cancer. Neuro Oncol. 2011; 13:1364-1369.

43. Pesce GA, Klingbiel D, Ribi K, Zouhair A, von Moos R, Schlaeppi M, Caspar CB, Fischer N, Anchisi S, Peters S, Cathomas R, Bernhard J, Kotrubczik NM, D’Addario G, Pilop C, Weber DC, et al. Outcome, quality of life and cognitive function of patients with brain metastases from nonsmall cell lung cancer treated with whole brain radiotherapy combined with gefitinib or temozolomide. A randomised phase II trial of the Swiss Group for Clinical Cancer Research (SAKK 70/03). Eur J Cancer. 2012; 48:377-384.

44. Chiu CH, Tsai CM, Chen YM, Chiang SC, Liou JL, Perng RP. Gefitinib is active in patients with brain metastases from non-small cell lung cancer and response is related to skin toxicity. Lung Cancer. 2005; 47:129-138. 